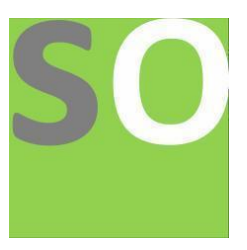

Article title: Binary Solvent Pretreatment, Adsorption and Definite Characterization of the Used Engine Lubricants. Authors: olabimtan Olabode[1], Williams Benjamin [2], Rihanat Mohammed [3], Mohammed Gero [4]

Affiliations: Department of Industrial and Environmental Pollution, National Research Institute for Chemical Technology Zaria Kaduna State, Nigeria.[1], Department of Chemistry, Faculty of Natural Science, University of Jos, Jos Plateau State, Nigeria.[2], Department of Integrated Science, Kogi State College of Education (Technical), Kabba, Kogi State.[3], Department of Textile, National Research Institute for Chemical Technology Zaria Kaduna State, Nigeria.[4] Orcid ids: 0000-0001-7736-8899[1]

Contact e-mail: olabode4angel@gmail.com

License information: This work has been published open access under Creative Commons Attribution License http://creativecommons.org/licenses/by/4.0/, which permits unrestricted use, distribution, and reproduction in any medium, provided the original work is properly cited. Conditions, terms of use and publishing policy can be found at https://www.scienceopen.com/.

Preprint statement: This article is a preprint and has not been peer-reviewed, under consideration and submitted to ScienceOpen Preprints for open peer review.

DOI: 10.14293/S2199-1006.1.SOR-.PP9BWN5.v1

Preprint first posted online: 09 February 2022

Keywords: Engine lubricant, methanol, n-hexane, activated charcoal, physicochemical characteristics. 


\section{Binary Solvent Pretreatment, Adsorption and Definite Characterization of the Used Engine} Lubricants.

\section{Olabimtan Olabode. $\mathrm{H}^{* 1}$, Benjamin Williams ${ }^{2}$, Mohammed Rihanat. $\mathrm{O}^{3}$,} Gero Mohammed ${ }^{4}$

\footnotetext{
${ }^{1}$ Department of Industrial and Environmental Pollution, National Research Institute for Chemical Technology Zaria Kaduna State, Nigeria.

2 Department of Chemistry, Faculty of Natural Science, University of Jos, Jos Plateau State, Nigeria.

${ }^{3}$ Department of Integrated Science, Kogi State College of Education (Technical), Kabba, Kogi State.

${ }^{4}$ Department of Textile, National Research Institute for Chemical Technology Zaria Kaduna State, Nigeria.

Corresponding author email: Olabode4angel@gmail.com
}

\section{Abstract}

Engine lubricants are viscous petrochemical products that are essentially formulated for the lubrication of moving parts in an engine. With the declining production of fossil oil reserves, the need to recycle used lubricating oils arises more than ever.

Coincidentally, engine lubricant loses its properties and cannot be used as required. Hence, this paper comparatively studies the treatment effects of the three months used lubricating oil (5W-30) with a binary solvent mixture [(methanol $(70 \%) / n$-hexane (30\%)] at a 5:1 solvent to oil mixing ratio with potassium hydroxide as a coagulant at $120^{\circ} \mathrm{C}$ and solvent expulsion for 30 minutes. The last stage of clarification was achieved with the physical adsorption of analytical grade activated charcoal at $150^{\circ} \mathrm{C}$ for 1 hour and centrifugation at $300 \mathrm{rpm}$ for 1 hour, resulting in a reddish-transparent colored base oil. Eight selected physicochemical parameters $(\mathrm{pH}$, specific gravity, dynamic viscosity, ash content, flash point, pour point, percentage water content, and metallic compositions) were evaluated with the fresh engine oil (FEO), three-month old engine oil (UEO), and the treated engine oil (TEO).

The results obtained at $95 \%$ confidence levels with respect to the entire parameters were significantly justified with the treatment methods that generated 95.7\% recovery. The approach has been demonstrated to be technically feasible, sustainable and ecologically friendly.
Keywords: Engine lubricant, methanol, n-hexane, activated charcoal, physicochemical characteristics.

\subsection{Introduction}

Lubricant is being used in automobiles to overcome frictional impact with wear, remove pollutants from the engine, and operate as a cleansing, cooling, and anticorrosive agent. It absorbs a variety of pollutants and other components from the engine system over time, including metal particles of iron, steel, copper, lead, zinc, and other barium compounds, sulfur, water, dirt, burnt carbon, and ash ${ }^{1}$. Many additives are used in engine lubricants to prevent unwanted properties, majorly as oxidation inhibitors, pour point depressants, coloring agents, anticorrosion agents, and many other classes ${ }^{1}$. The existence of the oil base material, as well as the nature and quantity of pollutants in the lubricating oil as a result of operations, all play a role in the recycling of spent lubricating oils. Contaminants enter the system from both the outside air and the engine ${ }^{1-2}$.

Technically, engine lubricant is an important product needed in the operation of the internal combustion engine but is known to suffer degradation by temperature and other chemical reactions. Most notably, oxidation and the generation of reaction byproducts such as organic acids, ketones, and polynuclear aromatic hydrocarbons (PAHs) result in a dark, viscous, and potentially carcinogenic substance ${ }^{3}$. Heavy metals and hazardous chemical compounds such as benzene, chlorinated solvents, poly-cyclic hydrocarbons (PAHs), polynuclear 
aromatic hydrocarbons, and polychlorinated biphenyls (PCBs) are found in used lubricating oils ${ }^{4}$. Therefore, appropriate management of the used lubricants are required to circumvent the adverse effects imposed on man and his environment. Meanwhile, from an ecological point of view, the combustion of expired lubricating oils is not recommended, since such will pollute a volume of air equivalent to that required by an average individual for the length of three years ${ }^{5}$. Similarly, the adsorption of $\mathrm{Cr}$ and its compounds released by burning used oil can cause some types of cancer ${ }^{6}$. Because of the negative effects of improper used oil management on the environment and human health, options for regenerating these oils with the goal of producing new lubricants and other petroleumderived products must be explored. The yield of lubricant or engine oils obtained from re-refining used oils is higher than that obtained from virgin crude petroleum refining, resulting in a reduction of approximately $90 \%$ of the environmental impacts associated with the production of petroleum-derived lubricant oils ${ }^{7}$. Organizations, particularly those in major enterprises that employ lubricants, use physicochemical techniques to remove pollutants from spent oil at their own facilities. The restored oil is then used in additional industrial applications such as metal-rolling, gear lubricants, and cutting oil lubricants ${ }^{7}$. Regenerated oil cannot be used in vehicles' engines or gearboxes due to degradation, but this alternative offers the advantage of decreasing losses in each processing step ${ }^{7}$. Wasted lubricant management is a prevalent concern in many African countries, especially Nigeria,

where service stations discharge a substantial volume of old engine lubricant ${ }^{8}$. Several African countries have put in place policies and plans to manage the disposal of their used oil to protect the environment. In this direction, there have been various techniques such as acid-adsorbent treatment, vacuum distillation, hydrogenation, solvent extractions, and natural adsorbents for the reclamation of waste engine oil over time, with each method characterized by some level of limitations in either cost, sustainability, or environmental sustainability ${ }^{1-9}$.

Acid treatment, which is the addition of inorganic or organic acids, has been exploited with the advantage of a rapid decrease in $\mathrm{pH}$ of the waste oil matrix ${ }^{1}$. Ellela et al. $2015^{10}$ and Krop et al., 2021 11 investigated the hybrid properties of various mineral acids on natural adsorbents, as well as the environmental downsides related with their use. The process under vacuum is a low-pressure distillation method that allows for the purification of chemicals based on boiling point differences ${ }^{12}$.

Muna et al. 2017 vacuum distillated waste lubricating oil after the processes of dehydration and filtration, raising the carbon chain number from $\mathrm{C}_{10}-\mathrm{C}_{15}$ to $\mathrm{C}_{20}$ $\mathrm{C}_{25}{ }^{13}$. Similarly, Myung-soo et al. 2008 were able to achieve a 95\% treatment level with vacuum distillation of waste engine oil with crude atmospheric distillation residue ${ }^{14}$. There was also a comparative outcome of high-grade base oil by Eman and Abeer (2013) between vacuum distillation (84\%) and solvent extraction $(78 \%)^{15}$.

Hydrogenation remains a chemical condition that happens when molecular hydrogen reacts with another substance or element in contact with an active catalyst, such as platinum, nickel, or palladium, to decompose or stabilize organic compounds ${ }^{16}$. Similarly, Batov et al. (2018) concentrated on heavy oil waste processing, which combines oil waste pretreatment with subsequent hydro conversion processing in the presence of extremely effective ultrafine catalysts under approximately optimum circumstances ${ }^{17}$. Another method for separating complex compounds is liquid-liquid extraction, otherwise regarded as partitioning and solvent extraction ${ }^{18-19}$. This method uses two immiscible phases, typically water and organic solvent, to isolate metal complexes or mixture compounds depending on the relative solubilities between the liquid phases. A novel blend of solvent extraction and activated alumina was conducted by Osman et al., 2017 with significant treatment and efficiency ${ }^{20}$. Rashid et al 2013 , in the same vein, achieved the best results with the composite solvent as they explored the comparative treatment of waste engine oil with the single solvent (propane) and the composite solvent (butanol-propane \& butanone $)^{1}$. Solvent extraction and adsorption were confirmed to be more successful processes for recycling waste lubricating oils in the findings of Durani et al., 2002 21 , Mariana et al., $2019^{22}$, and Kamal \& Khan, 2009 ${ }^{23}$. Osman et al. 2017 
investigated blends of at least two solvents with activated alumina as an adsorbent, with the defined oil-solvent ratios resulting in greater treatment yields ${ }^{20}$. Mohammed et al. 2013 investigated the use of adsorbent materials, which included almond shell, eggshell, walnut shell, and locally prepared acid activated clay, with an impressive outcome ${ }^{24}$. Hydrocarbon solvents, such as stabilized liquefied petroleum condensate, can also be utilized to lower the lubricating oil's carbon residue, asphaltene, and ash content ${ }^{25}$. Because of their ability to establish hydrogen bonds, Khan and Kamal (2009) discovered that solvents can be classified according to Burrel's categorization, which claims that alcohols are highperformance solvents while hydrocarbons are lowcapacity solvents ${ }^{23}$. Activated charcoal remains an adsorbent that has been shown to be technically active in the removal of a range of organic molecules from water, and oil ${ }^{26}$.

Because it is a very porous substance with a wide surface area for pollutants to adsorb to, it remains a good adsorbent ${ }^{27}$. It is made from carbon-rich materials, including wood, coal, and other substances that are burned at high temperatures between 600 and 900 degrees Celsius to produce charcoal powder $^{28}$. Because of its adsorption capacity, activated carbon is useful for recovering used engine oil. The work by Temple et al.,2020 used the bark of the Anacardium Occidentale tree to make activated charcoal for recycling spent engine oils with significant results in terms of flash point, viscosity, water content, fire point, and pour points at the end of 6 months $^{29}$. Riyanto et al. (2018) adopted 1butanol and potassium hydroxide as solvents and precipitators, respectively, to investigate the effects of metallic treatment on discarded lubricating oil with activated carbon. They affirmed that the waste lubricating oil treatment by the adsorption method using activated carbon significantly remediated the level of metals with the exception of $\mathrm{Pb}$ and $\mathrm{Fe}^{30}$. Abdulkareem et al. 2014 employed distillation method in association with acid, activated clay and charcoal comparatively with the pre-treatment process on Mobil and Total engine lubricants in order to improve their reuse properties ${ }^{31}$. Water content, specific gravity, kinematic viscosity, viscosity index, flash point, pour point, sulphur content, and heavy metal concentrations were all measured in the fresh, used, and treated oil. The sulphur of both brands of oil samples was clearly below the detectable level, but that of the used oil samples was detectable, as it was demonstrated that the general treatments were able to improve the features of the used oil samples after treatment. The distillation/clay and activated/charcoal procedures were found to be the most effective (80\%) in terms of oil recovery following treatment ${ }^{32}$. Another interesting scenario, was where Ammar (2005) achieved an activated carbon of good quality prepared from spent lubricating oils using an oxidation condensation process with 2 weight \% of $\left(\mathrm{CoCl}_{2}, \mathrm{ZnCl}_{2} \& \mathrm{FeCl}_{3}\right)$ with the stream of air or oxygen at $350^{\circ} \mathrm{C}$ for $(12,24 \& 36) \mathrm{hrs}$, followed by removal of uncarbonized materials under reduced pressure.

The carbonization, activation, purification, and drying processes eventually yield a good quality activated carbon with an oxidation rate of $2 \% \mathrm{FeCl} 3$ for $36 \mathrm{hrs}^{33}$. In this context, the restoration of spent (3-month) engine oil using co-solvent and activated charcoal was conducted in addition to the comparative physicochemical evaluations against the same brand of virgin (new) engine oil sample at standard conditions.

\subsection{Materials and methods}

The following items were obtained: used (3 months) and new synthetic Mobil 5W-30 engine oil, analar grade activated charcoal, glass beakers, thermometer, conical flask, separating funnels, measuring cylinder, evaporating dish, vacuum filtration system, laboratory centrifuging, temperature programmed heating mantle, pycnometer, flash point tester, analar grade methanol, n-haxane, magnetic stirrer, potassium hydroxide. 


\subsection{Pretreatment of the used lubricating oil sample.}

The used (3 months) 5W-30 lubricant sample was heated to $130^{\circ} \mathrm{C}$ to boil out emulsified water and some of the gasoline diluents. It was left to settle for a day at room temperature before being filtered to overcome suspended solids ${ }^{1}$.

\subsection{Treatment with a composite solvent (methanol/n-hexane).}

$500 \mathrm{ml}$ of the pretreated engine oil was mixed with a composite solvent of $70 \%$ methanol and $30 \% \mathrm{n}$ hexane at a solvent to oil ratio of 5:1, and then $3 \mathrm{~g}$ of potassium hydroxide according to Adewole et al., 2019 was added as a coagulant. The mixture was thoroughly stirred for about 30 minutes and then heated at $60^{\circ} \mathrm{C}$ under atmospheric pressure to remove light hydrocarbons through solvent extraction. The mixture was thereafter allowed to settle in a separation flask for 24 hours and then heated at $120^{\circ} \mathrm{C}$ to remove the solvent from the mixture ${ }^{34}$.

\subsection{Treatment with Activated Charcoal.}

$450 \mathrm{ml}$ of the prepared engine oil obtained from the oil-solvent mixture was reacted with $20 \mathrm{~g}$ of activated charcoal at $150^{\circ} \mathrm{C}$ for 1 hour. The heated mixture was allowed undisturbed for 2 hours at room temperature to allow for gravity settling and was then filtered under vacuum with subsequent centrifugation at 3000 rpm for an hour, obtaining a dark red transparent base oil ${ }^{33}$.

2.4 Physicochemical characterization of the used (UEO), fresh (FEO) and treated oil (TEO) samples

The $\mathrm{pH}^{35}$, specific gravity ${ }^{36}$, dynamic viscosity ${ }^{37}$, ash $^{38}$, flash point ${ }^{39}$, pour point ${ }^{40}$, water content ${ }^{41}$ and metallic compositions were conducted accordingly 42 .

\subsection{Percentage recovery}

After a chemical process, percent recovery calculates the proportion of an original substance that is recovered. Purification reactions are a good example of this. It also determines how effective they are. Percent recovery refers to the quantity of a product acquired following its formation and purification. The accuracy of the chemical reaction can be determined using the percent recovery ${ }^{43}$. 


\subsection{Results and discussion}

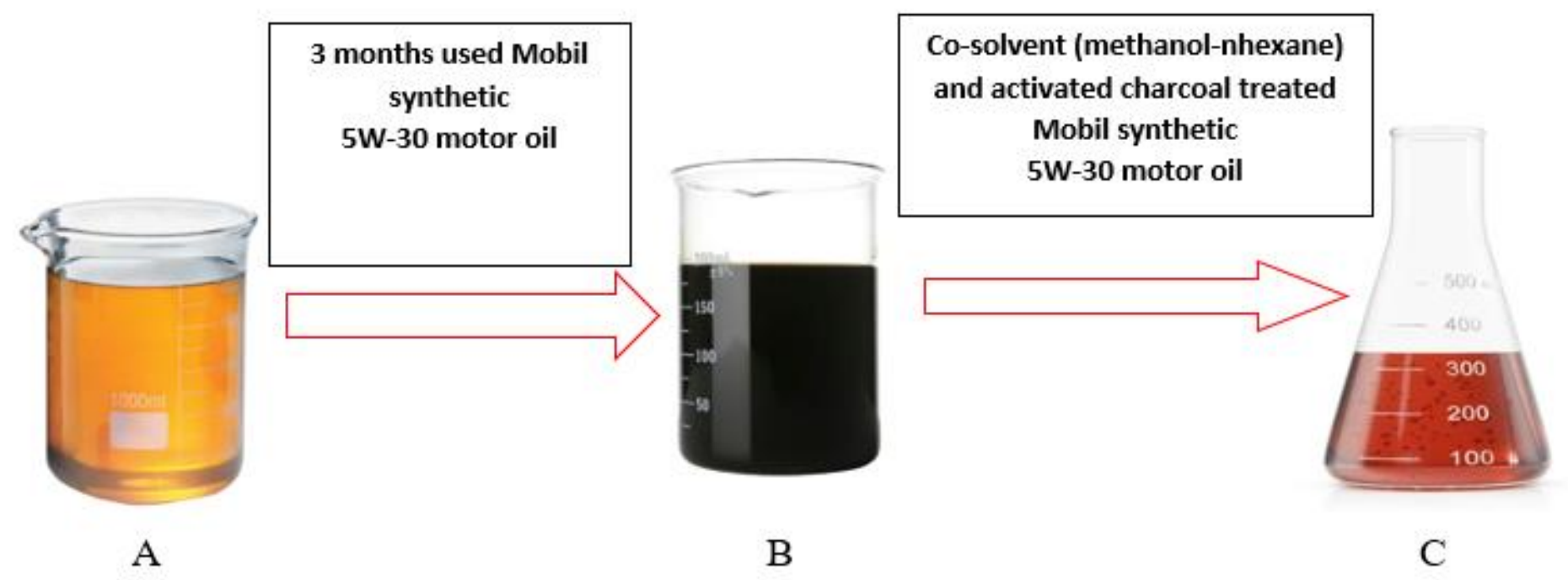

Figure 1. A. Fresh Mobil 5W-30 synthetic motor oil

B. Used (3months) Mobil 5W-30 synthetic motor oil

C. Treated 5W-30 synthetic Mobil motor oil 
Table 1. Selected physicochemical parameters of fresh (FEO), used (UEO), treated (TEO) Mobil synthetic $5 \mathrm{~W}-30$ motor oil samples

\begin{tabular}{|c|c|c|c|c|c|c|c|c|c|c|}
\hline \multirow[t]{2}{*}{$\mathrm{S} / \mathrm{N}$} & \multirow[t]{2}{*}{$\begin{array}{c}\text { TEST } \\
\text { PARAMETER }\end{array}$} & \multicolumn{3}{|c|}{$\begin{array}{l}\text { FRESH ENGINE OIL } \\
\text { (Standard) }\end{array}$} & \multicolumn{3}{|c|}{$\begin{array}{l}\text { USED ENGINE OIL } \\
\text { (3 months) }\end{array}$} & \multicolumn{3}{|c|}{ TREATED ENGINE OIL } \\
\hline & & $1^{\text {ST }}$ RUN & $2^{\mathrm{ND}} \mathrm{RUN}$ & $3^{\text {RD }}$ RUN & $1^{\text {ST }}$ RUN & $2^{\mathrm{ND}} \mathrm{RUN}$ & $3^{\mathrm{RD}} \mathrm{RUN}$ & $1^{\mathrm{ST}} \mathrm{RUN}$ & $2^{\mathrm{ND}} \mathrm{RUN}$ & $3^{\mathrm{RD}} \mathrm{RUN}$ \\
\hline 1 & $\mathrm{pH}$ & 7.8 & 7.6 & 7.6 & 5.9 & 6.0 & 5.9 & 6.9 & 6.8 & 6.9 \\
\hline 2 & $\begin{array}{l}\text { Specific Gravity } \\
\left(a 25^{\circ} \mathrm{C}(\mathrm{g} / \mathrm{ml})\right.\end{array}$ & 0.7010 & 0.7009 & 0.7010 & 0.8952 & 0.8855 & 0.8856 & 0.6632 & 0.7011 & 0.6621 \\
\hline 3 & $\begin{array}{c}\text { Dynamic } \\
\text { Viscosity (Pa s) } \\
\text { @. } 25^{\circ} \mathrm{C}\end{array}$ & 59.55 & 59.56 & 59.56 & 26.57 & 26.66 & 26.65 & 57.57 & 57.63 & 57.56 \\
\hline 4 & Ash, \% & 1.09 & 1.08 & 1.08 & 1.18 & 1.17 & 1.18 & 1.06 & 1.06 & 1.05 \\
\hline 5 & Flash Point ${ }^{\circ} \mathrm{C}$ & 200.00 & 199.00 & 199.00 & 136.00 & 135.00 & 136.00 & 196.00 & 197.00 & 197.00 \\
\hline 6 & Pour Point oC & -7.9 & -8.0 & -7.9 & -29.8 & -29.7 & -29.7 & -7.5 & -7.8 & -7.9 \\
\hline 7 & Water $\%$ & 5.00 & 4.62 & 5.01 & 15.50 & 16.02 & 16.02 & 4.52 & 4.51 & 4.52 \\
\hline \multicolumn{11}{|c|}{ Metallic Composition (ppm) } \\
\hline 8 & $\mathrm{Fe}$ & 0.98 & 0.98 & 0.97 & 95.55 & 96.47 & 95.55 & 1.04 & 1.03 & 1.04 \\
\hline 9 & $\mathrm{Cu}$ & 0.26 & 0.25 & 0.26 & 20.09 & 19.85 & 19.85 & 0.32 & 0.31 & 0.32 \\
\hline 10 & $\mathrm{~Pb}$ & 4.83 & 4.84 & 4.83 & 604.91 & 605.21 & 604.91 & 3.61 & 3.60 & 3.61 \\
\hline 11 & $\mathrm{Cr}$ & 0.17 & 0.17 & 0.17 & 1.27 & 1.32 & 1.33 & 0.15 & 0.15 & 0.15 \\
\hline 13 & $\mathrm{Zn}$ & 1516.25 & 1516.26 & 1516.25 & 1724.19 & 1725.21 & 1725.21 & 1621.02 & 1620.03 & 1621.02 \\
\hline 14 & $\mathrm{Ca}$ & 1200.17 & 1200.17 & 1200.16 & 1300.21 & 1300.21 & 1300.21 & 1167.03 & 1166.04 & 1166.04 \\
\hline
\end{tabular}


Table 2. Descriptive statistics of selected physicochemical parameters of fresh (FEO), used (UEO) and treated (TEO) Mobil synthetic 5 W-30 motor oil samples

\begin{tabular}{|c|c|c|c|c|c|c|c|c|c|c|c|c|}
\hline \multirow[t]{2}{*}{ Parameter } & \multicolumn{3}{|c|}{ Average mean value } & \multicolumn{3}{|c|}{ 95\% Confidence Level } & \multicolumn{3}{|c|}{ Highest value } & \multicolumn{3}{|c|}{ Lowest value } \\
\hline & FEO & UEO & TEO & FEO & UEO & TEO & FEO & UEO & TEO & FEO & UEO & TEO \\
\hline $\mathrm{pH}$ & 7.7 & 5.9 & 6.9 & 0.3 & 0.1 & 0.1 & 8.0 & 6.0 & 7.0 & 7.4 & 5.8 & 6.8 \\
\hline $\mathrm{SG}(\mathrm{g} / \mathrm{ml})$ & 0.7009 & 0.8888 & 0.6755 & 0.0001 & 0.0138 & 0.0552 & 0.7010 & 0.9026 & 0.7307 & 0.7008 & 0.875 & 0.6203 \\
\hline $\begin{array}{c}\text { Dynamic Viscosity } \\
\text { (Pas) }\end{array}$ & 59.55 & 26.63 & 57.59 & 0.01 & 0.12 & 0.09 & 59.56 & 26.75 & 57.68 & 59.54 & 26.51 & 57.50 \\
\hline Ash (\%) & 1.08 & 1.18 & 1.06 & 0.01 & 0.01 & 0.01 & 1.09 & 1.19 & 1.07 & 1.07 & 1.17 & 1.05 \\
\hline Flash Point $\left({ }^{\circ} \mathrm{C}\right)$ & 199.33 & 135.67 & 196.67 & 1.43 & 1.43 & 1.43 & 200.76 & 137.10 & 198.10 & 197.90 & 134.24 & 195.24 \\
\hline Pour Point $\left({ }^{\circ} \mathrm{C}\right)$ & -8.0 & -29.7 & -7.7 & 0.3 & 0.1 & 0.5 & -7.7 & -29.6 & -7.2 & -8.3 & -29.8 & -8.2 \\
\hline$\%$ water & 4.88 & 15.85 & 4.52 & 0.55 & 0.75 & 0.01 & 5.43 & 16.6 & 4.53 & 4.33 & 15.1 & 4.51 \\
\hline $\mathrm{Fe}(\mathrm{ppm})$ & 0.98 & 95.86 & 1.04 & 0.01 & 148.71 & 1.42 & 0.99 & 97.18 & 1.05 & 0.97 & 94.54 & 1.03 \\
\hline $\mathrm{Cu}(\mathrm{ppm})$ & 0.26 & 19.93 & 0.32 & 0.01 & 0.34 & 0.01 & 0.27 & 20.27 & 0.33 & 0.25 & 19.59 & 0.31 \\
\hline $\mathrm{Pb}(\mathrm{ppm})$ & 4.83 & 605.01 & 3.61 & 0.01 & 0.43 & 0.01 & 4.84 & 605.44 & 3.62 & 4.82 & 604.58 & 3.60 \\
\hline $\mathrm{Cr}(\mathrm{ppm})$ & 0.17 & 1.31 & 0.15 & 0 & 0.08 & 0 & 0.17 & 1.39 & 0.15 & 0.17 & 1.23 & 0.15 \\
\hline $\mathrm{Zn}(\mathrm{ppm})$ & 1516.25 & 1690.14 & 1620.69 & 0.01 & 148.71 & 1.42 & 1516.26 & 1838.85 & 1622.11 & 1541.43 & 1690.14 & 1619.27 \\
\hline $\mathrm{Ca}(\mathrm{ppm})$ & 1200.17 & 1300.21 & 1166.37 & 0.01 & 0 & 1.42 & 1200.18 & 1300.21 & 1167.79 & 1200.16 & 1300.21 & 1164.95 \\
\hline
\end{tabular}



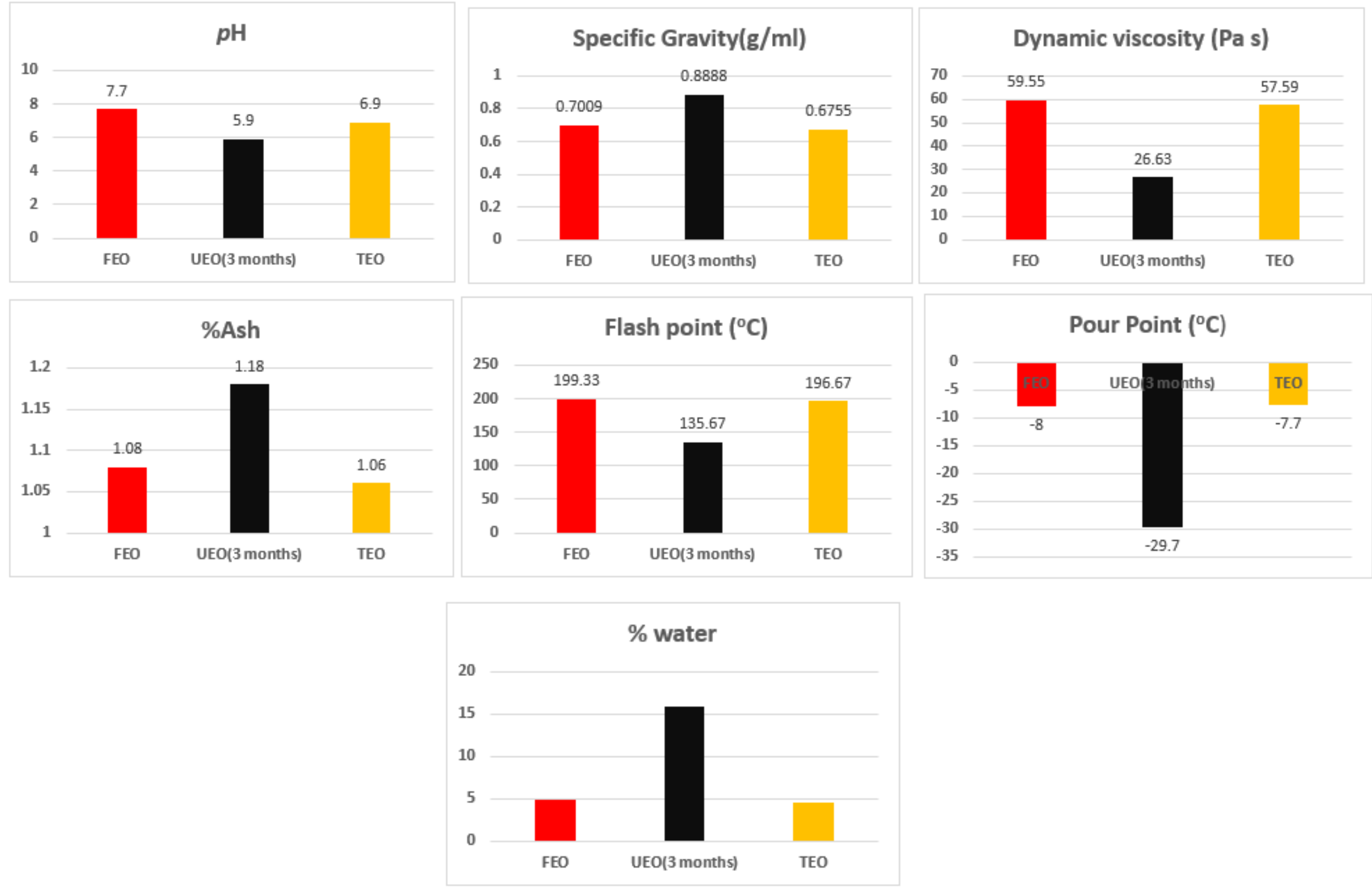

Figure 2. Physicochemical characteristics of fresh (FEO), used (UEO) and treated (TEO) Mobil synthetic 5W-30 motor oil samples. 


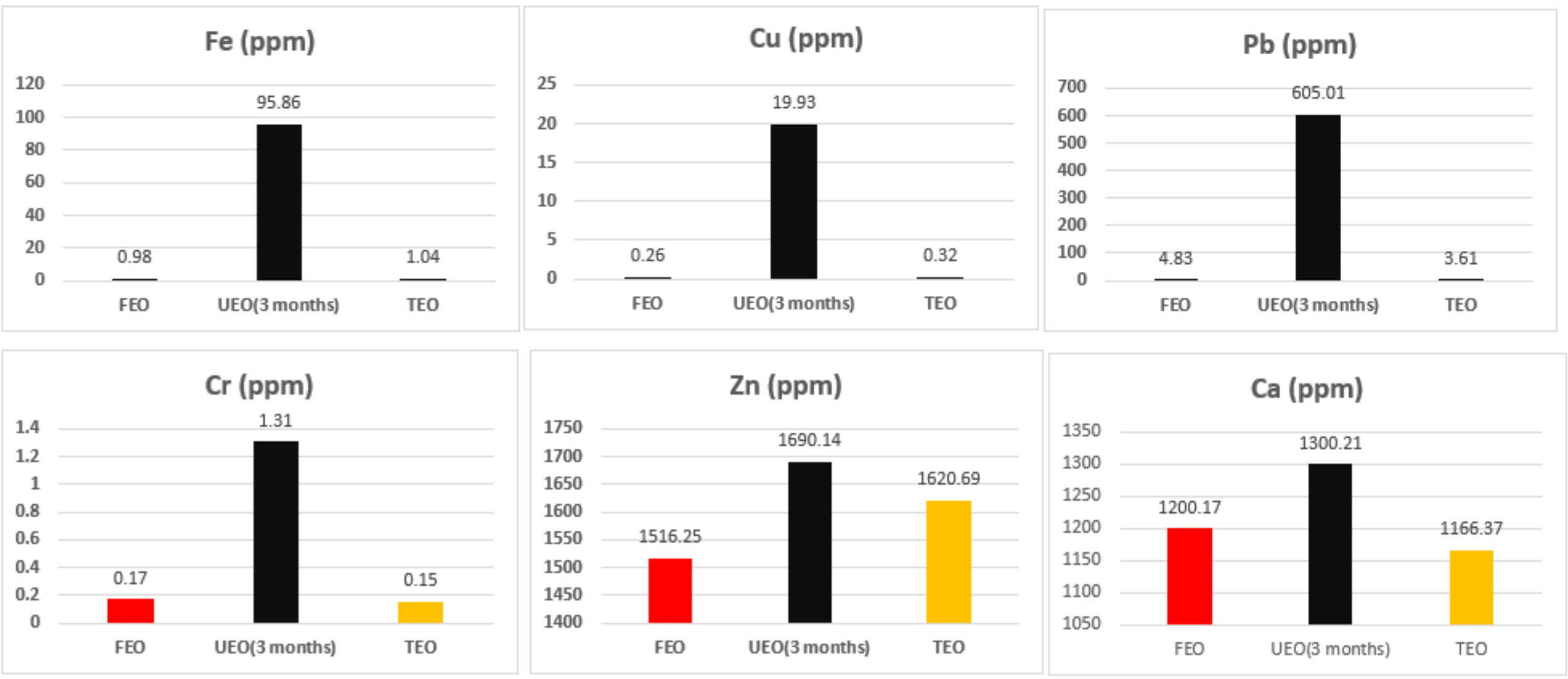

Figure 3. Metallic evaluations of fresh (FEO), used (UEO) and treated (TEO) Mobil synthetic 5 W-30 motor oil samples.

The net percentage recovery $=\underline{\text { The volume of the TEO }} \times 100$ The volume of the UEO

$$
=\frac{430.7}{450} \times 100=95.7 \%
$$


The methanol/n-hexane co-solvent system with activated carbon assisted adsorption treatment on the 3 months used $450 \mathrm{ml}$ of $5 \mathrm{~W}-30$ synthetic motor oil is depicted in Figure 1. Clearly, the possibility of reclaiming the used engine or lubricating oil to a level of $95.7 \%(438.7 \mathrm{ml})$ using an economically viable and sustaining method is practically a possibility. The fresh (FEO), used ( $400 \mathrm{ml}$, UEO) and treated engine oil (TEO) samples of the brand $5 \mathrm{~W}$ 30 synthetic motor oil was physiochemically evaluated at room temperature in triplicate

(Table 1). The $\mathrm{pH}$, which dictates the acidic and alkaline nature of the sample oils, illustrated the alkaline condition of the FEO, which erodes and degrades with time in its active state through the engine system into an acidic by-product, possibly due to the degree of corrosion by the action of hydrogen ion $\left(\mathrm{H}^{+}\right)$concentration ${ }^{44}$. Technically, $\mathrm{pH}$ is an essential determinant of how corrosive an oil is getting, which means that at some point, the $\mathrm{pH}$ begins to drop more rapidly, indicating that the oil needs to be changed ${ }^{45}$.

In Table 2 and Figure 2, FEO is considered the standard. The average mean values of UEO and TEO show some significant differences at a $95 \%$ confidence level, with the highest and the lowest values. These results also indicated that the hydrogen ion $\left(\mathrm{H}^{+}\right)$activity of the FEO, UEO, and TEO at a $95 \%$ confidence level cannot be greater than 8 , 6 , and 7 and cannot be less than 7.4, 5.8, and 6.8 respectively. The specific density of the lubricant is the proportion of the lubricant's mass to its absolute volume $^{46}$. According to Table 2 and Figure 2, the oil was classified as having a higher specific gravity with the UEO and a relatively similar specific gravity with the TEO. The 95\% confidence limit established the highest and least points with FEO, UEO, and TEO. The treatment process on the UEO $(0.8888 \mathrm{~g} / \mathrm{ml})$ reduces the specific gravity value to $0.6755 \mathrm{~g} / \mathrm{ml}$ (TEO) when compared to the value with FEO $(0.7009$ $\mathrm{g} / \mathrm{ml}$ ). The maximum value of $0.7302 \mathrm{~g} / \mathrm{ml}$ and the lowest level of $0.6203 \mathrm{~g} / \mathrm{ml}$ at a confidence level of $95 \%$ were statistically estimated. With the degree of the flow resistance between layers of the fluid, viscosity is also a dependable and crucial quality assurance characteristic of lubricating oil. A high viscosity indicates a significant resistance to flow, while a low viscosity shows a low resistance to flow $^{47}$. The lubricant's viscosity varies with temperature (inverse relationship) and pressure (direct relationship), improving the load carrying capability of the engine oil. These characteristics allow the engine oil to be used in heavy engines. Dynamic viscosity, in particular, is a representation of the fluid's intrinsic resistance to movement due to internal friction ${ }^{48}$.

Table 2 reveals the viscosities (dynamic) of the FEO (standard), UEO, and TEO at $250^{\circ} \mathrm{C}$. This could imply that viscosity will be reduced with increased usage of the lubricant (UEO) in terms of age and mileage. Hence, the reduction in the flow of resistance with the engine lubricant will result in a higher wear rate, reduced engine life, as well as increased maintenance $\operatorname{costs}^{49}$. However, the treatment process elevated the viscosity of the UEO (26.63 Pas) significantly with the mean average values of TEO (57.59Pas) in a relative magnitude to the FEO. When the lubricating oil is completely burned, the remaining solid is called ash, and it shows the oil purity ${ }^{1}$.

The ash percentage content with the UEO shows the degraded nature of the oil sample. However, the adopted treatment processes were able to significantly achieve some levels of control (1.06\%), with the oil sample having the highest and the lowest values at a 95\% confidence level. The ash content of the UEO (1.18\%) was treated to $1.06 \%$, with a maximum level of $1.07 \%$ and a minimum of $1.05 \%$ at $95 \%$ confidence levels. The flash point index of an engine oil can be defined as the temperature point where the vapor above the oil ignites momentarily with the introduction of an ignition source ${ }^{50}$.

This is quite different from pour point, which refers to the temperature level where the vapor above the oil ignites without an ignition source, as both parameters are reflections of the fire resistant and volatility characteristics of the lubricant ${ }^{50}$. The flash and pour points also confirm the level of adulteration of the oil ${ }^{51}$. Results on Table 2 show that the flash and fire points of the spent engine oil were reduced with an increase in time usage and mileage. Lubricants with low flash points that are below specification can cause a variety of engine problems, including crankcase explosions, as well as low lubricity due to high volatility, which can lead to engine wear and tear ${ }^{30}$. They also have limited rheological properties owing to excessive volatility, 
which can result in engine wear and tear. Results in Table 2 showed that the treatment approaches increased the flash point index of the spent engine oil $\left(135.67^{\circ} \mathrm{C}\right.$, upgrading it to the level of FEO at $196.67^{\circ} \mathrm{C}$ ). A maximum value of $198.10^{\circ} \mathrm{C}$ and the least value of $195.24^{\circ} \mathrm{C}$ were achieved. The average mean value with the UEO $\left(135.67^{\circ} \mathrm{C}\right)$ and the TEO $\left(196.67^{\circ} \mathrm{C}\right)$ declares the highest value of $198.10^{\circ} \mathrm{C}$ (TEO) and the least at $195.24^{\circ} \mathrm{C}$ at $95 \%$ confidence levels. Also, the pour point index of the spent oil after 3 months of usage is obviously above the standard value (FEO).

Basically, an increase in the pour point factor of a lubricant indicates the temperature point where the lubricant ceases to flow is fast and easily achievable, especially in tropical regions such as Nigeria, where it consequently prevents the engine from starting ${ }^{52}$. The estimation of the pour point with the UEO ($29.7^{\circ} \mathrm{C}$ ) was remediated to the point of $-7.7^{\circ} \mathrm{C}$ (TEO), which is also the highest against the standard (FEO). Results from Table 2 also show the percentage water content of the used lubricant increases with age and has values above the standard (FEO).

Fundamentally, water can have access to the lubricating oil through leakages from different parts, such as the engine coolant, oil cooler, and steam heating line ${ }^{53}$. The activity of moisture in the lubricating oil causes a lot of damage to engines. For instance, water oxidizes the base oil to form oxides, which further react with more water to form corrosive acidic substances ${ }^{54}$. Water can also lead to fractures caused by hydrogen release, which ultimately leads to pitting, etching, and fretting in bearings ${ }^{55}$. Water promotes corrosive microorganisms. Accumulated water causes condensation in the crankcase, resulting in oxidation of the oil ${ }^{56}$. However, the hydrophilic nature of the activated charcoal reduces the water content in the spent engine oil to acceptable levels ${ }^{30}$.

The average mean value of the TEO at $4.52 \%$ against the UEO of $15.85 \%$ shows a remarkable outcome from the treatment processes, with the highest value of $4.53 \%$ with a UEO of $6.6 \%$ and the minimum point at $4.51 \%$ with a UEO of $15.1 \%$ at a $95 \%$ confidence level. The average mean values of the selected metallic components ( $\mathrm{Fe}, \mathrm{Cu}, \mathrm{Pb}, \mathrm{Cr}, \mathrm{Zn}$, and $\mathrm{Ca}$ ), the highest and the least values at $95 \%$ confidence level are all declared in Figure 3 and Table 2.

Similarly, the average mean value of the TEO against the UEO is also Moreover, the levels of the selected metals were significantly predominant in the UEO sample and were eventually treated (TEO) as declared in Figure 3. Used engine oils include a wide range of metal concentrations that are introduced indirectly during usage through wear metals and lead through leaded gasoline. The category of natural surfactants and diluents applied to the fresh lubricant, storage and management measures all influence the magnitude of the pollutants in the fresh oil.

The table below summarizes the possible sources of metallic contaminants in the engine/lubricating oil $^{57}$.

Table 4. The Potential sources of metals in fresh (FEO) and used (UEO) engine/lubricating oils

\begin{tabular}{|c|c|c|}
\hline Metal & FEO & UEO \\
\hline Iron (Fe) & Iron bearing catalyst & $\begin{array}{l}\text { Crankshaft, engine block wear } \\
\text { and engine body damage }\end{array}$ \\
\hline Copper (Cu) & Copper bearing anti-oxidant and catalyst & $\begin{array}{l}\text { Some alloy bearing bushing, } \\
\text { and seal wear. }\end{array}$ \\
\hline Lead $(\mathbf{P b})$ & Lead salts anti-wear & $\begin{array}{l}\text { Leaded gasoline and alloy } \\
\text { bearing wear }\end{array}$ \\
\hline $\begin{array}{l}\text { Chromium } \\
\text { (Cr) }\end{array}$ & Chromium bearing catalyst & Piston rings and seal wear \\
\hline Zinc (Zn) & $\begin{array}{l}\text { Anti-wear and anti-oxidation additives; } \\
\text { Zinc bearing catalyst. }\end{array}$ & Unspecified engine wear \\
\hline Calcium (Ca) & Calcium salt detergents & Unspecified engine wear \\
\hline
\end{tabular}


Activated carbon or charcoal has been identified as an anti-wear additive which is capable of restoring the physicochemical characteristics to acceptable specifications ${ }^{58}$. The water content of the used engine lubricant will also be remediated to acceptable limits due to its hydrophilic nature against the activated charcoal. It also has the ability to inhibit wax formation in used engine oils at elevated temperatures owing to its capacity to reduce the pour point of the spent engine oil, thereby protecting engines from start-up issues ${ }^{30}$. It was also established that it has the ability to restore the fire and flash points of engine oil by adsorbing contaminants and volatile hydrocarbons responsible for its reduction, thereby saving the engines from damage such as crankcase explosions as well as other hazards ${ }^{30}$.

Generally, engine oil consists of $98 \%$ base oil and $2 \%$ additives. The base oil specifically does not get degraded but only gets dirty as the refining process isolates the contaminants and the additives ${ }^{59}$.

The quality of the used oil is eventually refined to be close to its original quality.

\subsection{Conclusion}

The environmental risks and threats posed by the indiscriminate discharge of old engine lubricant are serious enough to warrant immediate attention, necessitating the development of scientifically tested and proven methods for recycling spent oil. Because of the growing use of automobiles and other engines that are maintained by engine oils, recycling wasted engine oil is also critical in lowering the costs associated with purchasing new engine oils. The co-solvent (methanol/n-hexane) system with activated charcoal was found to be an effective hybrid formulation for recovering $95.7 \%$ of the engine oil's damaged quality metrics after three months of use. Basically, it should be acknowledged that the used oil resources identified are mainly industrial and transportation-based ${ }^{60}$.

Favorably, re-refining waste lubricants could secure both environmental and economic benefits by allowing for the production of base oil that uses less energy. The energy necessary to refine used oil into re-refined oil is one-third of that of refined crude oil into virgin base oil with the appropriate additives.

As a result, many people believe re-refining to be the best alternative for preserving lubricants limiting waste, and curbing environmental threat

\section{Acknowledgements}

The authors wish to appreciate the technical staff of the Department of Environmental and Industrial Pollution and Control of the National Research Institute for Chemical Technology, Zaria, Kaduna State, Nigeria, for their assistance during the experimentation period of this article.

Conflicts of Interest: The authors declare that they do not have any conflicts of interest. 


\section{References}

1. Rashid Abro, Xiaochun Chen, Khanji Harijan, Zulifqar A. Dhakan, Muhammad Ammar (2013). A Comparative Study of Recycling of Used Engine Oil Using Extraction by Composite Solvent, Single Solvent, and Acid Treatment Methods.

International Scholarly Research Notices, vol. 2013, Article ID 952589. https://doi.org/10.1155/2013/952589

2. Adewole, Bamiji Z., Joshua O. Olojede, Hakeem A. Owolabi, and Olaoluwa R. Obisesan (2019). Characterization and Suitability of Reclaimed Automotive Lubricating Oils Reprocessed by Solvent Extraction Technology. Recycling 4, no. 3: 31. https://doi.org/10.3390/recycling4030031

3. Patel, Avani Bharatkumar; Shaikh, Shabnam; Jain, Kunal R.; Desai, Chirayu; Madamwar, Datta (2020). Polycyclic Aromatic Hydrocarbons: Sources, Toxicity, and Remediation Approaches. Frontiers in Microbiology, 11(), 562813-. doi:10.3389/fmicb.2020.562813

4. Sprovieri M, Feo ML, Prevedello L, Manta DS, Sammartino S, Tamburrino S, Marsella E (2007). Heavy metals, polycyclic aromatic hydrocarbons and polychlorinated biphenyls in surface sediments of the Naples harbour (southern Italy). Chemosphere. Mar;67(5):998-1009. doi: 10.1016/j.chemosphere.2006.10.055. Epub 2006 Dec 8. PMID: 17157354.

5. Ferronato, N., \& Torretta, V. (2019). Waste Mismanagement in Developing Countries: A Review of Global Issues. International journal of environmental research and public health, 16(6), 1060. https://doi.org/10.3390/ijerph16061060
6. Wang, Y., Su, H., Gu, Y., Song, X., \& Zhao, J. (2017). Carcinogenicity of chromium and chemoprevention: a brief update. OncoTargets and therapy, 10, 4065-4079. https://doi.org/10.2147/OTT.S139262

7. Sánchez-Alvarracín, C., Criollo-Bravo, J., Albuja-Arias, D., García-Ávila, F., \& PelaezSamaniego, M. (2021). Characterization of Used Lubricant Oil in a Latin-American Medium-Size City and Analysis of Options for Its Regeneration. Recycling, 6(1), 10. doi:10.3390/recycling6010010

8. Nwachukwu, A. (2012). Review and assessment of mechanic village potentials for small scale used engine oil recycling business. African Journal of Environmental Science and Technology, 6(12), 464-475. doi: 10.5897/ajest12.091

9. Abdulkareem, A. S.; Afolabi, A. S.; Ahanonu, S. O.; Mokrani, T. (2014). Effect of Treatment Methods on Used Lubricating Oil for Recycling Purposes. Energy Sources, Part A: Recovery, Utilization, and Environmental Effects, 36(9), 966-973. doi:10.1080/15567036.2010.549920

10. R. Abu-Elella1, M.E. Ossman1,2, R. Farouq 1*, M. Abd-Elfatah1. (2015). Used Motor Oil Treatment: Turning Waste Oil into Valuable Products. International Journal of Chemical and Biochemical Sciences. (ISSN 2226-9614) www.iscientific.org/Journal.html

11. Krop, H., Eschauzier, C., van der Roest, E., Parsons, J., \& de Voogt, P. (2021). Independent mode sorption of perfluoroalkyl acids by single and multiple adsorbents. Environmental Science: Processes \& Impacts. doi: 10.1039/d1em00322d

12. Criscuoli, A. (2021). Osmotic Distillation and vacuum membrane Distillation for juice 
concentration: A comparison in terms of energy consumption at the permeate side. Separation and Purification Technology, 278, 119593. doi: 10.1016/j.seppur.2021.119593

13. Muna Mahmood Khudhair*, Tagreed Mahdi Hameed and Hader Abid Alameer. (2015). Using Vacuum Distillation Technique to Treat Waste Lubricating Oil and Evaluation its Efficiency by Chromatographic Methods. Journal of Al-Nahrain University Vol.20 (2), June,2017, pp.17-24.doi: 10.22401/JNUS.20.2.03.

14. Myung-Soo Kim, Jong-Sic Hwang \& HyungRak Kim (1997) Re-refining of waste lube oils by vacuum distillation with petroleum atmospheric residuum. Journal of Environmental Science and Health. Part A: Environmental Science and Engineering and Toxicology, 32:4, 1013-1024, DOI: $10.1080 / 10934529709376593$

15. A. J. Jafari; M. Hassanpour (2015). Analysis and comparison of used lubricants, regenerative technologies in the world. Resources, Conservation and Recycling .103 179-191.doi:

10.1016/j.resconrec.2015.07.026

16. Kitamura, M., \& Noyori, R. (2005). Hydrogenation and Transfer Hydrogenation. Cheminform, 36(39). doi: 10.1002/chin. 200539260

17. Batov A.E., Kadiev K.M., Kadieva M.K., Maximov A.L., Oknina N.V. (2018) Hydrogenation Processing of Heavy Oil Wastes in the Presence of Highly Efficient Ultrafine Catalysts. Proceedings of the Scientific-Practical Conference "Research andDevelopment. https://doi.org/10.1007/978-3-319-628707_69
18. Tshepelevitsh, Sofja; Hernits, Kertu; Jenčo, Jaroslav; Hawkins, Joel M.; Muteki, Koji; Solich, Petr; Leito, Ivo (2017). Systematic Optimization of Liquid-Liquid Extraction for Isolation of Unidentified Components. ACS Omega,2(11),7772-7776.

doi:10.1021/acsomega.7b01445

19. Raynie, Douglas E. (2004). Modern Extraction Techniques. Analytical Chemistry, 76(16),4659-4664. doi:10.1021/ac040117w

20. Osman, Doaa I.; Attia, Sayed K.; Taman, Afaf R. (2017). Recycling of used engine oil by different solvent. Egyptian Journal of Petroleum, S1110062116302161-. doi: 10.1016/j.ejpe.2017.05.010

21. N.O Elbashir; S.M Al-Zahrani; M.I Abdul Mutalib; A.E Abasaeed (2002). A method of predicting effective solvent extraction parameters for recycling of used lubricating oils., 41(9), 765-769. doi:10.1016/s02552701(02)00006-5

22. Mariana Busto, Enrique Eduardo Tarifa, Carlos Román Vera, (2018). Coupling Solvent Extraction Units to Cyclic Adsorption Units", International Journal of Chemical Engineering, vol. 2018, Article ID 1620218, https://doi.org/10.1155/2018/1620218

23. Kamal, A., \& Khan, F. (2009). Effect of Extraction and Adsorption on Re-refining of Used Lubricating Oil. Oil \& Gas Science and Technology - Revue d'IFP Energies nouvelles, 64, 191-197.

24. Mohammed, Rafie R.; Ibrahim, Inaam A.R.; Taha, Alladdin H.; McKay, Gordon (2013). Waste lubricating oil treatment by extraction and adsorption. Chemical Engineering Journal, 220(), 343-351. doi: 10.1016/j.cej.2012.12.076 
25. Ahmad Hamad; Essam Al-Zubaidy; Muhammad E. Fayed (2005). Used lubricating oil recycling using hydrocarbon solvents., 74(2), 153-159. doi: 10.1016/j.jenvman.2004.09.002

26. Rashed, M.Nageeb (2013). Organic Pollutants - Monitoring, Risk and Treatment // Adsorption Technique for the Removal of Organic Pollutants from Water and Wastewater., 10.5772/55953(Chapter 7), -. doi:10.5772/54048

27. Saleem, Junaid; Shahid, Usman Bin; Hijab, Mouhammad; Mackey, Hamish; McKay, Gordon (2019). Production and applications of activated carbons as adsorbents from olive stones. Biomass Conversion and Biorefinery . doi:10.1007/s13399-019-00473-7

28. Schth, Ferdi; Sing, Kenneth S. W.; Weitkamp, Jens (2002). Production and Applications of Activated Carbons. Handbook of Porous Solids.Volume1398., 10.1002/9783527618286, 1766-1827. doi:10.1002/9783527618286.ch24a

29. Chikwe T.N., Onojake M.C. and Orhuebor E.N. (2020). Recycling of "Spent Engine Oil" using Activated Charcoal Derived from Anacardium Occidentale. Chem. Sci. Eng. Res., (2020) 2(4), 52-57.

30. Riyanto, Agussetianingrum, Tri Astuti; Juliantydjawi, Dwi Putri; Ma'mun, S.; Tamura, H.; Purnomo, M.R.A. (2018). The effect of treatment with activated carbon on the metal content in reuse of lubricating oil waste. MATEC Web of Conferences, 154(), 01018-. doi:10.1051/matecconf/201815401018

31. A. S. Abdulkareem, A. S. Afolabi, S. O. Ahanonu \& T. Mokrani (2014) Effect of
Treatment Methods on Used Lubricating Oil for Recycling Purposes. Energy Sources, Part A: Recovery, Utilization, and Environmental Effects, 36:9, 966-973, DOI: $10.1080 / 15567036.2010 .549920$

32. Ammar A. Hamdon (2005).Production of Activated Carbon from Spent Lubricating Oils by Chemical Treatment

Iraqi National Journal of Chemistry, 2005, Volume, Issue 18, Pages 216-225

33. Adewole, Olojede, Owolabi, Obisesan, (2019). Characterization and Suitability of Reclaimed Automotive Lubricating Oils Reprocessed by Solvent Extraction Technology. Recycling, 4(3), 31-. doi:10.3390/recycling4030031

34. Yash P Kalra (1995). Determination of $\mathrm{pH}$ of Soils by Different Methods: Collaborative Study, Journal of AOAC INTERNATIONAL, Volume 78, Issue 2, 1 March 1995,Pages310324, https://doi.org/10.1093/jaoac/78.2.310

35. Tur'yan, Y., Kardash, E., \& Garibyan, I. (2007). $\mathrm{pH}-$ Metric Determination of Free Fatty Acids in Oils and Fats During Frying in the Absence of a Chemical Laboratory. Journal of The American Oil Chemists' Society, 85(1), 91-92. doi: 10.1007/s11746-007-1167-9

36. Wietecha, T., \& Kurzydło, P. (2019). Determination of the dynamic viscosity coefficient of the Stokes viscometer construction of a measuring set in the Physical Laboratory of the State Higher Vocational School in Tarnów. Science, Technology and Innovation,5(2), 60-65.doi: 10.5604/01.3001.0013.2885

37. Chukwuneke, Chikaodili E.; Madu, Joshua O.; Agboola, Bolade O. (2020). Determining Ash Content and Trace Metal Concentration in Crude Oil Samples to Teach Students Sample 
Preparation and Instrumental Analysis. Journal of Chemical Education, acs. jchemed.0c00494-.

doi: 10.1021/acs.jchemed.0c00494

38. Hameed, D. (2021). Engine Oil Deterioration based on the Viscosity, flash point and fire point for Different Trip Length. Kurdistan Journal of Applied Research, 13-20. doi: 10.24017/science.2021.1.2

39. Sokolnikov, A.N.; Bezborodov, Yu.N.; Shram, V.G. (2016). Apparatus for Determining of the Pour Point of Crude Oil and Petroleum Products. Procedia Engineering,150(),486489.doi: 10.1016/j.proeng.2016.07.023

40. Acker, M.M.; Frediani, H.A. (1945). Determination of Water Content in Oils. Industrial \& Engineering Chemistry Analytical Edition, 17(12), 793-794. doi:10.1021/i560148a016

41. Goncalves IM, Murillo M, González AM (1998). Determination of metals in used lubricating oils by AAS using emulsified samples. Talanta.;47(4):1033-42. doi: 10.1016/s0039-9140(98)00186-6. PMID: 18967407.

42. Sharon. B, Richard. P, Therese. F, Shonna. R, \& Jean D. (2021). Theoretical yield and percent yield.https://chem.libretexts.org/Bookshelves/I ntroductory_Chemistry/Book\%3A_Introductory _Chemistry_(CK12)/12\%3A_Stoichiometry/12.0 9\%3A_Theoretical_Yield_and_Percent_Yield

43. Huang, Y., \& Zhu, Y. (2005). Hydrogen ion reduction in the process of iron rusting. Corrosion Science, 47(6), 1545-1554. doi: 10.1016/j.corsci.2004.07.044

44. Popoola, Lekan; Grema, Alhaji; Latinwo, Ganiyu; Gutti, Babagana; Balogun, Adebori (2013). Corrosion problems during oil and gas production and its mitigation. International
Journal of Industrial Chemistry, 4(1), 35-. doi:10.1186/2228-5547-4-35

45. Headley, J., Peru, K., \& Barrow, M. (2015). Advances in mass spectrometric characterization of naphthenic acids fraction compounds in oil sands environmental samples and crude oil-A review. Mass Spectrometry Reviews, 35(2), 311-328. doi: 10.1002/mas. 21472

46. Piroozian, Ali; Ismail, Issham; Yaacob, Zulkefli; Babakhani, Parham; Ismail, Ahmad Shamsul Izwan (2012). Impact of drilling fluid viscosity, velocity and hole inclination on cuttings transport in horizontal and highly deviated wells. Journal of Petroleum Exploration and Production Technology, 2(3), 149-156. doi:10.1007/s13202-012-0031-0

47. Yang, X., \& Melnik, R. (2008). Dynamic analysis of polymeric fluid in shear flow for dumbbell model with internal viscosity. Journal of Central South University of Technology, 15(S1), 17-20. doi: 10.1007/s11771-008-0305-3

48. Carden, Phil; Pisani, Carl; Andersson, Jon; Field, Ian; Lainé, Emmanuel; Bansal, Jai; Devine, Maryann (2013). The Effect of Low Viscosity Oil on the Wear, Friction and Fuel Consumption of a Heavy-Duty Truck Engine. SAE International Journal of Fuels and Lubricants, 6(2), 311-319. doi:10.4271/201301-0331

49. Hameed, D. (2021). Engine Oil Deterioration based on the Viscosity, flash point and fire point for Different Trip Length. Kurdistan Journal of Applied Research, 13-20. doi: 10.24017/science.2021.1.2

50. S. Azadmard-Damirchi. S \&, Torbati. M. (2015). Adulterations in Some Edible Oils and Fats and Their Detection Methods. Journal of 
Food Quality and Hazards Control 2 (2015) 38-44.

51. Hameed, D. (2021). Engine Oil Deterioration based on the Viscosity, flash point and fire point for Different Trip Length. Kurdistan Journal of Applied Research, 13-20. doi: 10.24017/science.2021.1.2

52. Lodi, Faisal; Zare, Ali; Arora, Priyanka; Stevanovic, Svetlana; Jafari, Mohammad; Ristovski, Zoran; Brown, Richard J.; Bodisco, Timothy (2020). Combustion Analysis of a Diesel Engine during Warm up at Different Coolant and Lubricating Oil Temperatures. Energies,13(15),3931-.

doi:10.3390/en13153931

53. Johnson, David W. (2018). Lubrication Tribology, Lubricants and Additives |Antioxidants Classification and Applications in Lubricants., 10.5772/intechopen.69833(Chapter 2), -. doi:10.5772/intechopen.72621

54. Eliaz N. (2019). Corrosion of Metallic Biomaterials: A Review. Materials (Basel, Switzerland),12(3),407. https://doi.org/10.3390/ma12030407

55. Egharevba, F., \& Maduako, A. (2002). Assessment of Oxidation in Automotive Crankcase Lube Oil: Effects of Metal and
Water Activity. Industrial \& Engineering Chemistry Research, 41(14), 3473-3481. doi: 10.1021/ie000648k

56. Stout, Scott A.; Litman, Eric; Blue, Douglas (2018). Metal concentrations in used engine oils: Relevance to site assessments of soils. Environmental Forensics, (), 1-15. doi:10.1080/15275922.2018.1474288

57. Tanemura, K., \& Rohand, T. (2020). Activated charcoal as an effective additive for alkaline and acidic hydrolysis of esters in water. Tetrahedron Letters, 61(44), 152467. doi: 10.1016/j.tetlet.2020.152467

58. Anjana Srivastava1* \& Preeti Sahai2 (2013). Vegetable oils as lube base stocks: A review. African Journal of Biotechnology Vol. 12(9), pp.880-891 http://www.academicjournals.org/AJB. DOI: 10.5897/AJB12.2823.ISSN 1684-5315 C2013 Academic Journals

59. Ogbuigwe, A. (2018). Refining in Nigeria: history, challenges and prospects. Appl Petrochem Res 8, 181-192. https://doi.org/10.1007/s13203-018-0211-z

60. Alao, R., \& Payaslioglu, C. (2021). Oil price uncertainty and industrial production in oilexporting countries. Resources Policy, 70, 101957.doi:

10.1016/j.resourpol.2020.101957 
